\title{
The Policy Challenges of the Integration Strategy in the European States
}

\author{
Iraj Roudgar* \\ PhD in Policy Studies
}

*Corresponding Author: Iraj Roudgar, PhD in Policy Studies

\begin{abstract}
The migrant integration strategy is developed instead of migration policies and adopted in response to the recent forcibly displaced people across new-destination states. This paper discusses the policy challenges in the integration which provide a perspective from a political approach on the strategy in the European states. This discussion concludes the complexities challenges in cultural-political participation require greater attention and a suitable platform.
\end{abstract}

Keywords: Integration, Participation, political Culture, Policy Challenge

\section{INTRODUCTION}

European states have long been the top choice for international migrants from North Africa and the Middle East (MENA). The rise of the Islamic State (2014) as Islamic extremist group has brought civil wars and political instability and also a new pattern of forcibly displaced which the movement of large numbers of migrants to Europe. It represents one of the largest influxes of displaced people since the end of World War II. The flows of unauthorized immigrants from the MENA and managing the global refugee crisis are a common problem which remained at the top of the European Union agenda. According to the United Nations, the number of international migrants worldwide has continued to grow rapidly over the past fifteen years, reaching 244 million in 2015, and about 76 million are living in Europe (UN, 2016). Over the course of 2015, an estimated 1.3 million people applied for asylum in the European Union. In July 2018, Greek officials warned that they were unable to cope with tens of thousands of migrants held on islands in the Aegean Sea. The influx of migrants into Europe also has demonstrated the EU inefficiency policies in borders controlling. In a part of this social phenomenon, the forces migration in European Union has brought a social-political threat in the region. So, the EU policymakers are under the increasing public and political pressures to resolve the flows of unauthorized immigrants' crisis in the States. The integration strategy sets a framework for Government's approach to the issues of migrant integration processes and it is central importance to the participation of immigrants. This review has focused on policy challenges inmigrant participation in host community.

\section{A Critical Debate on Migration and InTEgration Policies}

The migration policies contain in summary all the legal norms which are in relation to human migratory movements or the changes in residential status being able to affect migratory trends and their effects and not only the labuor market consequences. ${ }^{2}$ The EU's migration policies proved inefficient to uphold proper standards of human rights protection and the right to asylum. It has also brought an uncertain society as an internal threat to homeland security interests linked to the mobility and security. In 2014, International Migration Policies described; the Governments' views and policies concerning international migration for 196 countries and concluded: Migration policies play an important role in determining the flows, conditions and consequences of international migration. The fight against migrant smuggling has been part of the EU policy to tackle migration for more than a decade. However, the migrant flows and in particular migration by sea, primarily along the Central

\footnotetext{
${ }^{1}$ (Eurosat, 2016)

${ }^{2}$ (Oltmer, 2017).
} 
and Eastern Mediterranean routes, has increased exponentially over the past years (UN, 2014). These high levels of informality are also coupled with public hostility towards migrants.

The principles of human rights and democratic values are working like a double-edged sword, and in some cases, it prevents the implementation of security in society. Obviously, the denial of basic rights makes migrants victims of social exclusion and increases their vulnerability in diverse areas of life. The democratic accountability by the European Parliament continues to be by and large limited and sometimes completely circumvented, which remains a profound weakness at times of monitoring and scrutinizing the EU's cooperation with third countries. ${ }^{3}$ Furthermore, the global humanitarian arena supports migrants in the European countries. Thus, the human rights aspect of immigrant and refugee integration policies was a successful policy implementation by the Council of Europe member states.

Lack of integration could have negative effects besides those on the main areas of competitiveness, the democratic representation, and accountability. The integration strategies set a framework and should cover all the key areas of growth and well-being: labour market, education, welfare system, housing environment, or civic and political life - systematically, such as how urban development strategies have to be worked out. ${ }^{4}$ Thus, the migrant integration strategy has progressively been becoming ever more important over the last decades. The integration is the process of becoming an accepted part of society. The dimensions of becoming an accepted part of society are legal, economic, and religious in the host countries. As the European Commission, the successful integration into society in the host country is the key to maximizing the opportunities of legal migration and making the most of the contributions that immigration can make to EU development. Immigration contributes to long-term growth by enhancing the human capital of the receiving economy and thus innovation, productivity and its competitiveness on the international markets. Both at EU and Member States levels awareness rose that the accumulation of human capital by means of both international recruitment and education are crucial for the achievement of the targets of creating more and better jobs and sustainable growth.

The implications of population ageing and population decline amongst many of the European countries are now alarming. In the Europe, population decline is now a phenomenon affecting more than one third of Europe's cities and these demographics have major impacts on both aggregate productivity growth and the distribution if resources between age cohorts. ${ }^{5}$ Recognition of cultural differences, granting rights to immigrants without a selective procedure (legal requirements) can be advantageous for immigrants but not for the host population, undermining the development of the welfare system. ${ }^{6}$ Consequently, the actual demand for foreign labour, as well as sensitive social and cultural issues should be considered. From the perspective of the outcomes of the integration strategy, it is important to distinguish the cultural dimension of these since it is permanently at the centre of controversies as for its definition or measurability. ${ }^{7} \mathrm{~A}$ cooperative attitude of the regional or local government regarding integration of immigrants and the priority of information transfer among the all actors (local community, immigrants, institutions, authorities, entrepreneurs, civil groups, and media)profoundly affect the outcomes of the labour market and thus both the social and economic development of the region. ${ }^{8}$

Lack of an effective platform for cultural and political participation into host communities has impact on the inclusion of migrants. So, the integration was unsuccessful in cultural-political dimensions particular in secular' country and religious' person, political religion and participation, equality, beliefs, practices and rituals of another group. The cultural adaptation and the main components such as language and religion are important factors to integrate. The political inclusion is a key factor in integration strategy and also a vital component in sustainable democracy. In the political culture area, the migrants' political perceptions and actions associated with the historical vision of national identity and societal self-development and moral ideal of the consumer impact on their participation. This historical identity-political culture- will become increasingly useful in analyzing the potential for

\footnotetext{
${ }^{3}$ (Guild, E. and S. Carrera, 2013)

${ }^{4}$ (Patay, 2017),

5 (Sharma, 2016)

${ }^{6}$ (Barry, 2001)

${ }^{7}$ (Treibel, 2011)

${ }^{8}$ (PATAY, 2017)
} 
future conflict between the migrants' family and native-born populations. Thus, the policy challenges in the short-term impacts with long-term results of the migrant integration strategy and their impacts are remained in the European communities; further investigation would be needed to assess the outcomes.

\section{CONCLUDing REMARKS}

The vicious policies circle in the migrants' country of origin has brought poverty and political instability which it's the major cause of the forcibly people movement to developed nations. As an opportunity for the effects of population ageing and population decline on economic growth, the migration has been the major source of population increase in the destination countries for their labour and force markets which it is a significant contributing factor in sustainable development goals and economic growth at the national and regional level, as a solution. The EU human rights aspect of refugee integration policies also was a successful policy implementation in context of migrant rights. Hence, the integration policies were fostered for economic inclusion and facilitated human right, but in the cultural-political participation policy implementation was so difficult to achieve, yet. The migrant historical identity will become a potential towards major challenges. The complexities challenges in cultural-political inclusion require greater attention and a suitable platform to achieve.

\section{Policy AND Managerial IMPLiCATIONS}

The migrant integration policy challenges is sustainable in the European communities and have a potential for a major migrant challenge in society, particular in term of political cultural for new generation immigrants, as a long-term approach. The migrant perception of social citizenship and their own and others' roles in society in the recent developments/integration from socialization and governance perspective also will bring a political challenge for policymakers. For EU policymakers, the complexities challenges in cultural-political inclusion need more attention rather than to the economic growth as well as potential solutions for the inclusion. Establishing a mechanism and suitable platform such online media for cultural and political participation into host communities is a vital component to promote community participation and engagement.

\section{REFERENCES}

[1] Barry, B. (2001). Culture and equality: an egalitarian critique of multiculturalism. Harvard Press, Cambridge, MA.

[2] Eurosat. (2016).

[3] Guild, E. and S. Carrera. (2013). EU Borders and their Controls: Preventing unwanted movement of people in the EU? CEPS Essay. CEPS Essay.

[4] Muysken, P. D. (2008). Immigration Can Alleviate the Ageing Problem. EIPASCOPE, 4.

[5] Oltmer, J. (2017). Globale Migration - Geschichte und Gegenwart [Migration -. Globale Migration.

[6] Patay, T. (2017). A Comparative Analysis of Migration Policies:. ACTA UNIV. SAPIENTIAE, ECONOMICS AND BUSINESS, 5, (2017) 139-154.

[7] Sharma. (2016). The Demographics of Stagnation: Why People Matter for Economic. Foreign Affairs, 17-24.

[8] Treibel, A. (2011). Migration in modernen Gesellschaften - Soziale Folgen von. Juventa Verlag, Weinheim.

Citation: Iraj Roudgar. "The Policy Challenges of the Integration Strategy in the European States" International Journal of Political Science (IJPS), vol 5, no.4, 2019, pp. 24-26. doi: http://dx.doi.org/10.20431/2454-9452. 0504004.

Copyright: (1) 2019 Authors. This is an open-access article distributed under the terms of the Creative Commons Attribution License, which permits unrestricted use, distribution, and reproduction in any medium, provided the original author and source are credited. 